\title{
Study on Resistant Action of Environmental Mass Incidents
}

\author{
Delong Gao", Li Wang ${ }^{2}$, * \\ ${ }^{1}$ Center for Digitalized Culture and Media, School of Political Science and Public Administration, University of Electronic Science and \\ Technology of China, Chengdu, China \\ ${ }^{2}$ School of Political Science and Public Administration, Center for Digitalized Culture and Media, University of Electronic Science and \\ Technology of China, Chengdu, China
}

Email address:

sin205@foxmail.com (Delong Gao), s_peacock@163.com(Li Wang)

${ }^{*}$ Corresponding author

\section{To cite this article:}

Delong Gao, Li Wang. Study on Resistant Action of Environmental Mass Incidents. Humanities and Social Sciences.

Vol. 5, No. 6, 2017, pp. 215-221. doi: 10.11648/j.hss.20170506.14

Received: September 25, 2017; Accepted: November 25, 2017; Published: December 6, 2017

\begin{abstract}
Environment and resources have become the obvious problems with the rapid development of China, as a result, the resistant action of the public in environmental events becomes increasingly frequent. The mechanism of public collective action in environmental events is investigated in this paper through the qualitative comparative analysis on 13 public resistances against environmental issues during 2010-2014. The study finds that politics, scientific cognition, rumor, appeal, media, actio and disposal of pointing person are the key factors for the resistant action of environmental mass incidents. The risk perception and scientific cognition of mass against environmental projects are affected by information imbalance, in which rumors may aggravate the development of events and trigger violence among the public. In the Internet era, network public opinion can bring more attention to events, and reports from the central media reflect political "metaphor". It is an effective path to avoid environmental mass incidents for government to share the decision-making power with the public in managing environmental projects based on information dissemination and communication.
\end{abstract}

Keywords: Environmental Events, Resistant Action, Case Study, Qualitative Comparative Study

\section{Introduction}

The booming Chinese economy is accompanied by many problems. One of these problems is environmental issues which have attracted more and more public attention.

Sudden environmental events have become the focus of the study in the existing research, of which the research contents include technical monitoring, emergency plan, government information disclosure, rumor dissemination, etc. Mass incidents caused by environmental events may originate from the explanation of environmental events based on the theory of "not in my backyard" (NIMBY) from the sociological perspective, such as site selection of PX project, or from the concern with government's information publicity and countermeasures in environmental emergencies from the perspective of government governance, or from the investigation on the general burst process of unexpected events and countermeasures by placing the environmental events under the vision of sudden mass incidents.
Different from demolition, labor conflicts, judicial justice, moral privacy and other issues, environmental issue has its own particularity. It is related to the health rights and interests of human, which belongs to the consideration scope of personal security, and essentially belongs to the human existence right. Secondly, environmental problems are characterized with strong scientificity, such as the cause of fog and haze and toxicity of dioxins. This makes the environmental group events polymorphic and complex. What we will work out in this paper are what the resistant action in environmental mass events is, what the result is and what the solution is. This paper has conducted qualitative comparative analysis on 13 typical cases of environmental mass incidents, regarding event direction, emotional expression, interest demands, rumor dissemination, environmental science cognition, network public opinion, offline action, policy and media reports as consideration factors of environmental resistance action events. Moreover, it has attached much importance on factors which affect mass resistance action in 
environmental events and are easier to win.

\section{Literature Review}

With the development of economy, the environmental problems caused by resource consumption in China have become increasingly prominent, and the resistant actions against environmental issues also have increased. The relevant responsible person of the environmental protection department also admits that environmental petition and safeguard for legal rights along with mass incidents increase year by year. The trends of increase in number, participation enhancement, scale and universality and so on appear in the group resistance events caused by environment. Some scholars put forward that the concept of environmental mass incidents may refer to the incidents of mass protests and resistance caused by environmental pollution with a certain number of individual participation through the non-normal channels to express their demands [1]. And some scholars believe that environmental mass incidents are group behaviors with certain territoriality, scale, predictability, repeatability and harmfulness caused by environmental problems. To safeguard the legitimate rights and interests infringed by environmental problems, some people appeal collectively, block traffic, besiege Party and government organizations and factories, doing harm to industries and governments [2].

Environmental mass incidents belong to resistant action. And this problem has been studied in many fields such as sociology, politics, communication, psychology, law, etc. Some scholars believe that efforts should be made to improve the credibility of the government, that is, it shall set up the correct view of official achievements in order to change the mode of economic growth practically, unblock the channels of interest demands to protect the citizens' participation and strengthen the supervision of environmental law enforcement to improve the environmental legal system for the governance of environmental mass incidents from the perspective of government governance [3]. Some scholars argue that the government should improve and revise the environmental standards, eliminate the conflicts and blind spots in the field of environmental legislation, introduce the precautionary principle of environmental risks, and perfect the channels of judicial remedy for citizens in environmental rights from the legal angle [4]. Starting from the causes of events, Zheng Xutao puts forward the five dimensional analysis framework on the basis of case analysis; it is considered that the five dimensions of social background, root of conflict, political governance, group psychology, organizational mobilization can explain the causes of environmental mass incidents [5]. Some scholars conclude from the empirical research that the frequent outbreak of environmental mass incidents is highly related to economic development and pollution; it is characterized by strong regionalism with pollution problems accounting for the highest proportion, the resistant appeal is unitary, and the difference between urban and rural areas is large with huge mobilization scale; the first exposure media is mainly the forum, etc [6]. Some scholars think that NIMBY mass events show a high incidence trend from NIMBY effect; and the governance for the risk of NIMBY conflict becomes a problem that all levels of government must face with [7]; and this kind of resistance is hard to apply to rural areas in terms of the generation condition of NIMBY conflicts [8]; the settlement of environmental conflicts in urban areas is easy to promote the NIMBY facilities to transfer to rural areas, which could lead to even more serious environmental conflicts. In the Internet era, Li Chunlei. et al conclude from the case-based analysis that the network greatly reduces the risk costs of being involved in actions; and the relational network with realistic participation attributes is constructed by using micro-propagation, which serves as the basic condition for the consensus spread of micro-communities at the same tim [9]. The literature review reflects that the study on environmental mass incidents has the following characteristics: the intervention of multi-disciplines makes the study on environmental mass incidents more thorough; most studies focus on influencing factors; a small number of studies also adopt empirical methods based on case study; from the perspective of multi-theories, the theory is interpreted led by the NIMBY effect and social movement, etc. Environmental mass incidents can be simply regarded as the public group resistance incidents caused by environmental pollution or environmental risks. In the process of investigating the environmental mass movement, most of the existing research focus on the individual case-based analysis; the influencing factors of case is thoroughly analyzed; but outbreak causes, resistance purpose, the degree of resistance and the results should be considered as an investigation aspect of environmental mass incidents in the overall resistant action. The key factors of environmental mass incidents or the relationship between condition and event result are studied with the method of qualitative comparative analysis on basis of combing the event process with 7 aspects of politics, scientific cognition, rumor, appeal, media, action, and the attitude of pointed person as the influencing aspects of environmental mass incidents based on existing literature with classic case as original version.

\section{Research Methods and Design}

\subsection{Research Method}

Charles Larkin published the monograph "comparative methods" in 1987, and he first introduced the qualitative comparative analysis into social sciences. This research method integrates the analysis techniques such as set and Boolean algebra to combine the advantages of quantitative and qualitative research with case orientation. Qualitative comparative analysis can effectively deal with multi-cases comparison data, which has been widely used in industrial action, social movement, protest research and social revolution [11]. It is divided into clear set qualitative comparison and fuzzy set qualitative comparison in 
utilization, it interprets the event factors as that variables interpret the different paths of the same result through conditions and results under the guidance of set logic.

It conducts the dichotomy disposal for the explanatory variables and outcome variables on basis of event categorization, classification, attribute judgment, comparison of attributes and construction diversity of factors, 1 or 0 is assigned to the read of variables. Therefore, the assigned 1 of variable means "true", that is, "yes" or "existent"; the assigned 0 of variable means "false", that is, "no" and "non-existent". The cause condition and outcome condition are assigned respectively in specific instances, and the data of each instance is represented with truth tables. The dichotomy method is a sort of qualitative comparative analysis for clear set, which can handle explanatory variables and outcome variables. It is just $\mathrm{s}$ case which can process dichotomic variable. The explanatory variable assumes a degree in real social phenomenon, therefore, some scholars put forward the theory of fuzzy sets. Different subordinated index number shall be divided between 0 and 1 , and the intersection and union operations shall be carried out for the sets. As a case-study-oriented method, QCA can help researchers to conduct the dialogue between theories with experience and systematically analyze small and medium-sized sample data [12].

The main reasons for the QCA research method selected in this paper are as below: environmental mass incidents are a kind of performance of public resistant action, resulting in complex conditions of such social phenomena and complex factors affecting the generation, action and outcome of the resistant action. Environmental mass incidents have the complexity and uncertainty of various combinations of factors, and in QCA analysis, the occurrence factors which lead to a certain result are multiple. The resistant outcome of environmental mass incidents is obviously divided into successes or failures, and the outcome variable set belongs to general dichotomic variable.

\subsection{Case Selection}

The extracted cases in this paper occur during 2010-2014, the media coverage and research on the case base are regarded as the source of case samples. The typicality and importance shall be criteria for case selection. The typicality of case mainly refers to the influence intensity of the environmental mass incidents on the incident place, the exposure degree in media and the study situation of incident. The importance of case refers to the variation of environmental mass incidents to the environmental project construction, environmental protection of incident place and public awareness for the environment. On the one hand, typical cases can fully reflect the whole process of research event, on the other hand, it also refers to the event that can be fully grasped and considered with retrospective data. Thirteen cases of the 5 years are selected as samples for qualitative comparative analysis after the consistency detection of coder; the qualitative comparative analysis generally selects more than 12 cases. The specific selected cases are as follows:
Table 1. Case selection.

\begin{tabular}{ll}
\hline Case & Time \\
\hline Site change disturbance of Guangxi Guanyang refuse landfill & 2010 \\
Anti-power plant construction in Haimen, Shantou & 2011 \\
PX project event in Dalian & 2011 \\
Waste incineration power plant in Songjiang, Shanghai & 2012 \\
PX event in Ningbo, Zhejiang & 2012 \\
Pengze nuclear power construction & 2012 \\
Jiangsu Qidong incident & 2012 \\
Shifang molybdenum copper project incident in Sichuan & 2012 \\
Tianjin PC "green" chemical project & 2012 \\
"Poisonous factory" incident in Shenzhen & 2013 \\
PX project in Anning, Kunming & 2013 \\
Maoming anti-arene project & 2014 \\
Yuhang Zhongtai waste incineration plant incident & 2014 \\
\hline
\end{tabular}

\subsection{Design for Explanatory Variables}

The design of explanatory variables is mainly conducted from three aspects: political opportunities and appeals, cognition and discourse modeling, media and strategy utilization. Based on literature analysis and empirical observation, 7 factors of politics, scientific cognition, rumors, appeals, media, actions and attitude of pointed person are established. And these 7 factors have a clear logical relationship, that is, the burst of environmental mass incidents is prompted under the influence of multiple factors, which also generates the confrontation with different degrees, and these factors affect the reach of resistance purpose. There are 2 basic claims at the same time as the explanatory variables are determined. First, the public is aware of the risks of projects related to the environment, this perception of risk is an instinctive awareness and vigilance of human-beings about the changes in the surrounding environment. Secondly, the public in environmental mass incidents has a clear demand, such as suspending construction, relocation or economic compensation. The achievement of these demands or the resistant objective is an important symbol of measuring the resistant action after the occurrence of mass incidents. It is generally believed that the outbreak of environmental mass incidents can achieve the resistant purpose. In specific cases, it cannot be reached though some environmental mass incidents are fierce and violent action appears.

Political factor mainly refers to citizen's participation, that is, if the citizens are involved in decision-making in different ways when government formulates the project or EIA related to environmental risks. Lack of public participation, opaque government decision-making and non-disclosure of procedures are important factors affecting environmental mass incidents through literature review. Therefore, the public is not involved in the formulation of relevant decisions, with assignment of 1 . And the decision-making process with public participation and hearing of public opinion is assigned as 0 . Scientific cognitive attainment enables the public to scientifically and rationally treat to some projects, avoiding following other information blindly due to the cognitive problems of project, especially the rumors. Therefore, the public in the event process with no scientific cognition is 
assigned as 1 and those that can understand some projects scientifically are assigned as 0 . The opacity of government decision-making, lack of public scientific cognition and non-disclose of information in the process of project construction can cause the spread of rumors. Some rumors directly point at the power-money transaction, some exaggerate the project hazards, some point to that the incident can cause casualties and so on. Rumors are an important factor in intensification of event to the vicious transition. Therefore, the events which spread rumors and intensify the development are assigned as 1 , otherwise 0 . Some scholars point out that network public opinion can affect the trend of event development in the Internet era, which causes the attention of the decision-making department and solve the problem quickly. If the network public opinion appears in the event, presenting a nationwide network of public opinion, that is, the events are reported on various major platforms, lasting for more than 5 days, the assignment shall be 1 , otherwise 0 . And the report from central media indicate that the incident is taken seriously, and the reports from central media often prompt the government in the incident place to take measures to deal with it properly. If central medias report that the incident is in succession, it shall be assigned to 1 , otherwise 0 . The outbreak with results of mass incidents has close relationship, the reach of resistant result is a composite result of the mutual influence between the mass and the government, or it can be said as the result of mutual compromise. The value for all resistant purposes reached and appeal achieved is assigned as 1 , otherwise 0 .

Table 2. Definition and assignment for variables.

\begin{tabular}{|c|c|c|}
\hline \multicolumn{3}{|c|}{ Definition and assignment for variables } \\
\hline Factor & Variable & Variable Assignment \\
\hline Political Factors & Policy Formulation & $\begin{array}{l}\text { No citizen participation in policy making: } 1 \text {; } \\
\text { Citizen participation in policy making: } 0\end{array}$ \\
\hline Scientific Cognition & Scientific Literacy & $\begin{array}{l}\text { Lack of scientific cognition: } 1 \\
\text { Correct scientific cognition: } 0\end{array}$ \\
\hline Rumor Factor & Rumor Spreading & $\begin{array}{l}\text { There are rumors and making things worse: } 1 \text {; } \\
\text { No rumor or with little effect: } 0\end{array}$ \\
\hline \multirow{2}{*}{ Communication Media } & Online Opinion & $\begin{array}{l}\text { It shows nationwide network public opinion: } 1 \text {; } \\
\text { Non-national: } 0\end{array}$ \\
\hline & Central Media & $\begin{array}{l}\text { Reports from the central media: } 1 \text {; } \\
\text { Other media reports: } 0\end{array}$ \\
\hline Offline Action & Offline Action & $\begin{array}{l}\text { More than } 100 \text { persons take actions or with act of violence: } 1 \text {; } \\
\text { Otherwise } 0\end{array}$ \\
\hline Attitude of Pointed Person & Coping Attitude & $\begin{array}{l}\text { Improper disposal or negative and silent response: } 1 \\
\text { Correct disposal: } 0\end{array}$ \\
\hline Result & Outcome Variable & $\begin{array}{l}\text { Successful resistance or demand satisfaction: } 1 \\
\text { Failure or non-satisfaction:0 }\end{array}$ \\
\hline
\end{tabular}

\section{Qualitative Comparative Analysis}

\subsection{Construction of Truth Table}

Selected typical cases shall be coded according to the analysis and construction of explanatory variables and outcome variables and it shall be assigned accordingly based on the actual situation. The assignment of typical cases is explained and summarized; the truth table is therefore obtained through organizing the composite data. Truth table is the basic data of analysis based on qualitative comparative analysis, and the truth table is as follows.

Table 3. Truth table.

\begin{tabular}{|c|c|c|c|c|c|c|c|}
\hline \multicolumn{8}{|c|}{ Truth table } \\
\hline Policy & Scientific cognition & Rumor & Online opinion & Central media & Offline action & Response & Resistance result \\
\hline 1 & 0 & 1 & 1 & 1 & 1 & 1 & 1 \\
\hline 1 & 0 & 1 & 0 & 1 & 0 & 0 & 1 \\
\hline 0 & 1 & 0 & 1 & 1 & 1 & 0 & 0 \\
\hline 1 & 1 & 0 & 1 & 0 & 1 & 0 & 1 \\
\hline 1 & 1 & 1 & 1 & 1 & 0 & 0 & 0 \\
\hline 1 & 0 & 0 & 0 & 1 & 1 & 0 & 1 \\
\hline 1 & 1 & 0 & 1 & 0 & 1 & 0 & 1 \\
\hline 1 & 0 & 1 & 1 & 1 & 0 & 1 & 1 \\
\hline 1 & 0 & 0 & 0 & 1 & 1 & 1 & 0 \\
\hline 1 & 1 & 0 & 1 & 0 & 1 & 0 & 1 \\
\hline 0 & 1 & 1 & 1 & 1 & 1 & 0 & 0 \\
\hline 0 & 0 & 0 & 1 & 0 & 1 & 0 & 1 \\
\hline 1 & 0 & 1 & 0 & 1 & 1 & 1 & 1 \\
\hline
\end{tabular}




\subsection{Analysis on Single Variables}

In qualitative comparative analysis, whether there is a necessary and sufficient relationship among variables can be determined through consistency analysis and coverage rate calculation. Consistency is a certain given condition or condition combination that leads to the result to the extent which all case included in analysis are shared [13]. The coverage rate refers to that to which extent these given conditions or condition combinations can explain the outcome of result. The analysis on single variables is to explore whether the single variable constitutes a necessary condition or a sufficient and necessary condition for the success of resistance in environmental mass incidents. In the consistency testing of necessary conditions, a single variable is considered as a necessary condition if the index is greater than 0.9 .

Table 4. Consistency and coverage of variables.

\begin{tabular}{lll}
\hline Variables & Consistency & Coverage \\
\hline Policy & 0.888 & 0.8 \\
Literacy & 0.333 & 0.5 \\
Rumor & 0.444 & 0.666 \\
Online & 0.666 & 0.666 \\
Official media & 0.555 & 0.555 \\
Violence & 0.777 & 0.7 \\
Disposition & 0.333 & 0.75 \\
\hline
\end{tabular}

It is found from the analysis of single variable that the consistency indexes of each variable are less than 0.9 , which cannot constitute the necessary condition for the success of resistance in environmental mass incidents. The logical relation of explanatory variables and QCA consistency analysis indicate that the whole resistance process of environmental mass incidents is influenced by many factors. Explanatory variables have important significance for understanding the outbreak of environmental mass incidents, which have a very strong impact on the emergence of resistance action and results.

\subsection{Qualitative Comparative Analysis for Clear Set}

The path with higher coverage rate can be obtained by leading the truth table into QCA analysis software for analysis.

Table 5. The path with higher coverage rate.

\begin{tabular}{lll}
\hline Complex & Raw Coverage & Unique Coverage \\
\hline policy*literacy* $\sim$ rumor*online* official media*violence* disposition & 0.33 & 0.33 \\
policy* literacy*rumor*fficial media*violence*disposition & 0.22 & 0.11 \\
policy* $\sim$ literacy*rumor*online*official media*disposition & 0.22 & 0.11 \\
\hline
\end{tabular}

As shown in the picture, there are 3 kinds of paths with outbreak of environmental mass incidents of successful resistance and high coverage ratio, these 3 typical paths are as below:

Policy*literacy* $\sim$ rumor*online* $\sim$ official-media*violence* $\sim$ disposition (That is, lack of public participation + lack of scientific cognition + no rumor + nationwide network public opinion + no central media coverage + violence + proper disposal in the event process)

policy* literacy*rumor*official-media*violence*dispositi on (That is, lack of public participation + scientific cognition + rumor spread + central media coverage + violent resistance + improper disposal in the event process)

policy* literacy*rumor*online*official media*disposition

(That is, lack of public participation + scientific cognition + rumor spread + nationwide network public opinion + central media coverage + improper disposal in the event process)

We can analyze the outbreak of environmental mass incidents and the aims of resistance from these three paths. The first path shows that the lack of public participation, the nationwide network public opinion and violence are the key to the outbreak of environmental mass incidents with successful resistance. The absence of public participation affects the scientificity of decision-making and violates the legitimate procedures that the responsible government should have in decision-making from the perspective of social governance. This leads to the lack of better public understanding of policy information and lack of trust in government action, which may bury potential risks for decision making. Nationwide network public opinion not only proves that the public opinion cannot smoothly submitted and the government's reasonable and legitimate demands and channels of expression " lose voice", it can only be expressed in the form of public opinion. And the Internet leads to certain political opportunities for the mass to attract attention of the policy-making authorities with a view to solving the problem. Acts of violence are the means of expression that contradiction is further intensified and put into irrationality; there many beating, smashing and looting and bleeding cases in environmental mass incidents; acts of violence and passion in environmental mass incidents are not intended to explore in this paper, but it needs to be pointed out that such actions exactly bring about an expansion of events and the strengthening of the influence. In the second path, the lack of public participation, rumor spread, central media coverage, violent resistance and improper disposal during the event are the important causes of the outbreak of 
environmental mass incidents with victory resistance. From the view of government behavior, the lack of public participation and improper disposal of the incident just indicate that the government's ability to deal with issues related to environment needs to be strengthened. The spread of rumors shows that the information disclosure channels, information authority, scientificity are in a weak position. According to the current occurrence conditions of investigated rumors, the extent of relevance, insecurity and the uncertainty of the surrounding environment are the key to the emergency of gossip. Rumors are different from gossips, they are purely fabricated, but gossips in mass incidents are often full of rumors, this not only causes panic among the mass, but also tends to lead group behavior to extremes. CCTV media coverage exactly indicates the attention of central media to event, in which the official background of the central media has a major "metaphor"; the government in the incident place may properly handle the incident to promote the results of the event in line with the appeal of mass based on the intention of the central media reports. The third path is added with nationwide network public opinion compared to the second path. Generally speaking, the interaction between traditional media and Internet media is the prominent feature of network hot spot events. On the one hand, the nationwide network public opinion plus the official media background of traditional media can extend the influence power of events; on the other hand, it can promote social focus on the issue to make it become a social issue so as to facilitate the settlement of events.

\section{Conclusion and Discussion}

In the risk society, the essence of the generation of environmental problem is the result of irreconcilable contradiction among resources, energy and the development of human society, and thus it leads to the mass incidents relating to environmental projects, especially the chemical industry, energy, waste disposal and other projects. From the perspectives of political opportunities and appeals, it is found from the study that decision-makers in environmental mass incidents lack the considerations of public opinion. The lack of public participation in decision-making just reflect that there are problems in the management concept of government. The start of some projects is conducive to the development of local economy, and is conducive to the government to create good achievements. And the decision-makers may naturally think it is conducive to the development of local society and improvement of people's life so as to consider the correctness of the project. However, the lack of public participation just neglects the cognition and attitude of mass towards the project in respect of the management of risk project. The environmental problems that may exist in risk project can threaten the survival security of human, this "personal" threat may easily arise the vigilance of most people. From the prospective of the public, the distrust for policy makers, businesses and experts, along with the spread of rumors in events can cause a rise in public fears. And it is easy to form an attitude of antipathy and opposition with the addition of group emotional infection. The public will seek other ways if the legal appeal channel "loses its voice". Obviously the Internet provides an important way for the mass to express their voice, which is also one of the reasons why Chinese netizens utilize the Internet to express their appeals. The Internet has two important effects on environmental mass incidents: (a) the public opinion momentum is rising through the network, it provides the expression platform for the resistant activities, and this cyberspace resistance can arise the attention of policy makers; (b) the Internet is also an effective "contact" platform for protesters to initiate, disseminate and even organize the street protests of environmental mass incidents. Although the actions of cyberspace exactly expand the public participation channels and reduce the external barriers of the collective action of group organization that is far from the power center, and the network action can also draw attention of policy makers. However, taking a broad view of environmental mass incidents, the offline action, including mild "promenade" and violent protests, remains an important choice for protesters to face the environmental problems.

In the study of environmental mass incidents, the NIMBY effect is an important explanation theory for the environmental mass incident, but there are many reasons for its cause in reality, for instance, the simple NIMBY effect cannot fully explain the environmental mass incident caused by economic compensation. What's more, the public has expressed understanding and support for certain projects, but the distrust towards government and the qualification of project implementer lead to the occurrence of mass incidents. Starting from the theory of collective behavior, structural stress, triggering events, the weakening of the normal social communication system and the abnormal activity of propagation mechanism are the basic conditions for promoting mass behaviors [14]. Insecurity, discontent, anxiety, and panic will commonly exist in people's heart when they feel the potential crisis situation caused by the risk projects, which may plant seeds for the collective behaviors. And the spread of gossips or rumors deepen the stimulus, for instance, when environmental mass incidents occur, the "PX poison", "someone died at the scene", "police killed and trampled the people" and other information in cyberspace can easily lead to group hint and group infection, and it can quickly stimulate the offline resistant action. The information imbalance in decision-making process of government, low openness, improper disposal, silent and prevaricated attitude suffocate the local normal information dissemination. People are more inclined to unidentified rumors, what's more, the project itself involves the environmental risks and personal dangers.

This paper argues that the government shall pay attention to the basis of public opinion in the decision-making process of risk projects and share the decision-making power with the public in the decision-making process by combining the whole process of environmental mass incidents with the consideration of the causes and results. Taking the local government in the US. as an example, the government will announce the economic and social benefits, risks and other 
advantages and disadvantages bought by the construction, site selection and environmental impact assessment of nuclear power plants through media and forums and so on when they consider building the nuclear power plant. At the same time, it will promote the public participation in the discussion on the construction of nuclear power plants with the dissemination and popularization of relevant scientific knowledge of nuclear power. Risk communication achieved on this basis is a benign interaction between the government and the people. It is also the two-way communication between the government with the mass and the risk projects. Chinese local governments have now formed relatively favorable communication between government and people in respect of risk projects after many mass incidents, for instance, some local governments clearly indicate "they will never start it if most citizens do not understand and agree with the project". The settlement of the risk projects should be achieved with avoidance of the adversarial game between the public and government, which requires the government to convert the concept of risk management. The government shall fully provide all kinds of information related to the risk projects so that the level of communication between government and public can be promoted. The sufficient information provided can not only ensure that the public can participate in the decision-making, but also enhance the public's scientific cognition of risk projects and the acceptance ability of risk psychology. The government shall take the initiative to utilize the media to disseminate the risk project information involving the environment so as to achieve favorable communication. And it shall provide scientific and formal information for public, utilize the Internet to disseminate and popularize the scientific knowledge of relevant project, and actively disclose all the environmental impact assessment data and decision-making process. Reasonable compensation scheme shall be implemented. The reasonable financial compensation shall be conducted for the occupied land of site selection and the risks of residents in core area of site selection. The outbreak causes of environmental mass incidents and the resistant results are formed under the complex effects of various factors. The government and public should achieve favorable interaction with the purpose of communication and consensus. It is an effective way to avoid environmental mass incidents that utilizing the network media and official media to fully disseminate the decision-making information, risk project information, scientific popularization information and sharing the decision-making power of risk project management with the public.

\section{Acknowledgements}

Humanities and Social Sciences Fund of Ministry of Education "Research on the Dissemination of Scientific Information and Risk Communication from the Perspective of Risk Management" ( 16YJC860018);

Sichuan Social Science Key Research Base Project: "Research on Public Perception of Risks and Government Risk Prevention in the Dissemination of Scientific Issues" (SR16A03)

\section{References}

[1] Zhang Ping, Yang Zuchan. Brief analysis on the characteristics of environmental mass incidents in China over the past ten years [J]. Journal of China University of Geosciences (Social Sciences Edition), 2015, (02): 53-61.

[2] Zhang Youfu. Discussion on the main causes of environmental mass incidents and solutions [J]. Inheritance, 2010 (11).

[3] Liu Xiliang, Liu Xiuxiu. Analysis on the causes and countermeasures for environmental mass incidents based on the credibility of government [J]. Chinese Management Science, 2013, (S1): 153-158.

[4] Cheng Yuyan. Characteristics, causes and legal countermeasures of environmental mass incidents [J]. Journal of Guangdong Administrative College, 2007, (02): 46-49+81.

[5] Zheng Xutao. Analysis on the causes of preventive environmental mass incidents---- taking Shifang, Qidong and Ningbo cases as examples, [J]., Southeast academic, 2013, (03): 23-29.

[6] Rong Ting, Xie Yungeng. Occurrence, spread and respond of environmental mass incidents -- based on the empirical analysis of 150 major environmental mass incidents in China in $2003 \sim 2014$ [J]. News Reporter, 2015, (06): 72-79.

[7] Dong Youhong. The theory of "NIMBY conflict" and its enlightenment on the governance of NIMBY mass incidents [J] Journal of Shanghai Administrative College, 2013, (02): 21-30.

[8] Li Deying. NIMBY conflict and environmental contradictions in China -- based on the analysis on the causes of environmental conflicts and the differences between urban and rural areas [J]. Journal of Nanjing Agricultural University (Social Sciences Edition), 2015, (01): 89-98+126.

[9] Li Chunlei, Ling Guoqing. Study on mobilization mechanism of micro-communities in environmental mass incidents -based on the field investigation of Kunming PX incident [J]. Modern communication(Journal of Communication University of China), 2015, (06): 61-66.

[10] $\mathrm{Li} \mathrm{Yu}, \mathrm{He}$ Haibing. The study logic and application of qualitative comparative analysis [J]. Journal of Shanghai Administration College, 2015, (05): 92-100.

[11] Huang Ronggui, Zheng Wen, Gui Yong. Multi-channel strong intervention, framework and resistance results. Qualitative comparative analysis on fuzzy sets of 40 demolition resistance cases. [J]. sociological research, 2015, (05): 90-114+244.

[12] He Junzhi. Fuzzy set method in comparative political analysis [J]. Social Sciences, 2013, (05): 30-38.

[13] Guo Qingguang. Course of communication [M]. Beijing: Renmin University of China press, 2012., 84-88. 